\title{
Research on the Practice of Flipped Class Mode Based on the Platform of WeChat
}

\author{
Ling Zhang \\ Beijing Wuzi University, Beijing, China
}

\begin{abstract}
The main features of mobile application software are recognized as the potential for learning process to be personalized, spontaneous, flexible, and free. Although it may take a longer time to enable systematic learning through mobile phones compared to computers, the learners do receive a greater learning experience of freedom of time and place, so that they can take the advantage of spare time to learn a second language anywhere with a phone in hand. In this paper, by looking at most popular mobile applications-WeChat and its main mobile learning friendly characteristics, the author observes the ways to construct the WeChat-based flipped classroom on both theory and practice aspects. And on this basis, a flipped classroom model supported by the WeChat platform has been constructed. Furthermore, guided by the constructed flipped classroom model, the author carried out an experiment on teaching session in business English class. Fifty students participated in this WeChat-based flipped class experiment to analyze learners' attitude towards WeChat in language learning. The learning outcomes of two tests - one before WeChat and one after-are compared in this empirical study. The results show that learners think that WeChat gives them more target language exposure and more chances to communicate with teachers and other learners. The results of comparison indicate that WeChat-based flipped classroom can effectively improve the students' learning outcome.
\end{abstract}

Keywords: WeChat, flipped classroom, practice research

With the development of hand-held mobile communication technology, it has become a commonplace for users to watch videos on their smart phones. Naturally, using mobile technology to watch video of flipped class to carry out language learning has become the new direction for linguistics researchers. Using the hand-held mobile communication technology is a teaching innovation in linguistic lecturing, also it can improve the English teaching environment, and it can be an effective supplement to the current English teaching model. This paper is to focus on the most popular mobile phone software-WeChat to analyze language teaching outcome of flipped class mode based on WeChat. WeChat, a mobile phone chat software launched by Tencent company in early 2011, can send texts and photographs as well as supporting on-line chat through voice in group. Due to the powerful features and user-friendliness, WeChat enjoys nationwide popularization rapidly. It is especially widespread among college students, under this trend, mobile learning and micro learning are easily accessible. As a communication tool, WeChat offers public platform, circle of friends, news feeds, and other functions, it also can send user-defined-context to multiple users simultaneously, making WeChat - the multiple function software a possible tool in the linguistic teaching (Liu \& Jiang, 2015).

Corresponding author: Ling Zhang, MA, senior lecturer, Beijing Wuzi University, Beijing, China; research field: technology-assisted language acquisition. 


\section{The Possibility and Advantage of WeChat Platform-Aided Language Teaching}

\section{WeChat's Language-Friendly Functions}

WeChat supports most mobile platform systems, such as the IPhone, Android, Windows Phone, Symbian, etc., so it possesses widespread popularity among college students. The author randomly samples and investigates 235 undergraduate students at Beijing Wuzi University (BWU), whose WeChat utilization rate is as high as $97 \%$, making WeChat aided language teaching possible. WeChat has various functions, and some of the core functions can better meet the needs for language teaching, such as:

(1) Chat: It supports sending voice messages, video, images, and text and supports multiple people chatting at the same time;

(2) Real-time intercom function: Users can have real-time intercom in voice chat rooms with a group of people;

(3) Circle of friends: Users can post text and images among circle of friends, at the same time, they can share articles or music to a circle of friends by other software. Users can comment on photos newly posted by their friends with "comment" or "praise", and they can only see the same friends' comments or praises;

(4) Voice notepad: Users can undertake voice shorthand, and it also supports the video, pictures, and text;

(5) WeChat public platform: On this platform, individuals and businesses can create a WeChat public account to publicly post three categories' content, namely, text, pictures, and voice.

\section{How the Functions of WeChat Cater to the Characteristics of Language Teaching and Flipped Class}

Based on interactive and open features of WeChat platform, WeChat teaching platform can create various communicative situations by designing various kinds of learning tasks and learning activities, at the same time, WeChat's multiple functions can well meet the needs of language learning (see Table 1), the analysis of WeChat platform's applicability to educational function of flipped class is as follows:

Table 1

The Solution of WeChat-Based Flipped Classroom

\begin{tabular}{|l|l|}
\hline Functions of WeChat & Flipped classroom needs \\
\hline \multirow{3}{*}{ WeChat media platform } & Send the flipped classroom video \\
\cline { 2 - 2 } & Send the flipped classroom learning material \\
\hline \multirow{2}{*}{ Realtime communication } & Learning material trouble-shooting \\
\cline { 2 - 2 } & Communicative language environment \\
\cline { 2 - 2 } & Customized individual guidance \\
\cline { 2 - 2 } & Independent learning and community learning \\
\hline WeChat group and WeChat moments & Feedback gathering \\
\hline & Communicative comments \\
\hline
\end{tabular}

(1) The public platform function of WeChat can strongly support mobile learning and digital learning. Teachers can send language learning material to their friends or share it in the circle of friends for learners' independent learning, which can realize the release and sharing of learning resources and learning experience as well as supporting interactive commentary and study evaluation;

(2) WeChat's public platform can achieve packet transmission, push English learning related material, and realize real-time group chatting at any time;

(3) WeChat's real-time communication function can be used in inter-student discussion and 
communication as well as communication between teachers and students in order to reply timely to students' questions and provide personalized guidance;

(4) The group chat function can support collaborative learning within the group, which is convenient for discussion and communication as well as sharing resources;

(5) The function of adding friends can support finding friends by WeChat ID, QQ friends, and contacts, shared functions as WeChat ID and people nearby provide various ways to add new friends, which are easy to form a study group, easy to get access to learning resources, support, and help.

\section{The Construction of Flipped Classroom Model Based on WeChat}

\section{Theoretical Basis}

Constructivism. Constructivism believes that knowledge is self-constructed by learners' interaction with others. Learning is an active construction process instead of learners' passively absorbing knowledge. Therefore, flipped class should make full use of the educational application function of WeChat, so as to build a good personalized learning environment and to guarantee students' effective pre-class independent learning. In addition, during the classroom teaching, teachers should pay attention to creating learning situations, and combine with the effective form of learning activities to boost effective interaction between students' experience and the environment, so as to realize the meaningful knowledge construction (Qiu, 2014).

In view of this, the teaching activities should be placed in a meaningful context, and the ideal situation is putting what they have learned into practice. According to the principle of psychology, when learners do not depend on the external force and take the initiative to acquire knowledge, they would be more likely to achieve the ideal effect of learning. To practice and transform the teaching method is the fundamental guarantee of maintaining high learning motivation. Therefore, flipped class adopts task-based teaching, which can effectively motivate students' learning initiative, so as to achieve better learning effect.

Task-based teaching method. Task-based language teaching emphasizes the simulation of all kinds of real life activities in the classroom. It combines the language teaching and learners' language application in everyday life to cultivate students' ability to use English language in real life. How to design tasks which can meet the requirements of syllabus, and stimulate students' interest in learning, also be feasible and advantageous to the task of cultivating students' comprehensive ability, is the key of task-based language teaching. Flipped class is to arrange tasks in class based on the content of videos after they have watched the videos of knowledge before class, so that the students finish their tasks, solve the problems, build the knowledge structure, and acquire the knowledge at the same time.

Mobile-based language learning and community. The MALL (Mobile-Assisted Language Learning) study started from 1994, but it has become a hot topic from the emergence of smart phone which has a Wi-Fi device to connect to the internet and make the real-time on-line communication possible since 2006. As the technology advances, some criticisms toward the limitation of mobile phone have been settled by the emergence of new functions of smart phone. For instance, the technologies of Wi-Fi, 3G, and even 4G networks broaden the small bandwidth problem. Similarly, problems associated with manual text input are being resolved through the use of speech recognition technology and touch screens (Wang \& Smith, 2013). Since the emergence of smart phones in 2007, more and more functions specific to PCs (personal computers) and other hand-held devices have been integrated within mobile phone devices. The advancement of the mobile technologies makes it more suitable to be a language learning tool. Numerous researches have recommended 
MALL as a method of providing learners real-time collaborative learning experience. It has been shown that mobile phones are increasingly used for improving knowledge of vocabulary (Stockwell, 2010), grammar (Sung, Huang, \& Chang, 2006), listening (Liu \& Chu, 2010), and speaking (Rueckert, Kiser, \& Cho, 2012), other than the four basic language skills, mobile phones can also be applied to other learning situations, such as foreign culture acquisition (Comas-Quinn \& Mardomingo, 2009).

Smart phone is employed as a language learning tool in many fields to improve learners' language skills. For example, in the vocabulary acquisition field, some researches (Zhang, Song, \& Burston, 2011) are done to compare mobile-based vocabulary acquisition with paper-based one, the results show that students who learn through mobiles are found to learn more words than the ones do the paper-based tasks. Students have a positive attitude toward mobile-based language learning community. And numerous advocates have recommended MALL as a method of providing L2 learners with rich, real-time, cooperative, and conversational experiences both inside and outside the classroom.

But it is impossible to reach a consensus for all the researches in MALL. Notwithstanding its benefits, MALL also faces related challenges. There are some side effects need to take into consideration when a mobile-based language community is built. For example, compared with computer, mobiles have limited audiovisual quality, virtual keyboarding and one-finger data entry, and limited power. Except from the technological weaknesses, Colpaert pointed out a paradox of MALL, which is while mobile technologies are advancing, their output is quickly moving from verbal to visual, a clear disadvantage for language learning (Colpaert, 2004).

Through the analysis of the negative effects of MALL, Wang and Smith (2013) argued that some criteria must be followed in mobile-based learning to play to its strengths and compensate the weaknesses. The criteria include: (1) providing engaging learning materials that are not too long; (2) a proper degree of teacher monitoring; (3) student involvement; (4) the need for incentives; and (5) a respect for privacy (Wang \& Smith, 2013).

Students are very reluctant to concentrate on the long and exhausting materials, they usually have a short attention span on the mobile learning materials. Delivering smaller chunks of materials - such as mini-essays and grammar quizzes - may be more suitable for better mobile phone learning experiences (Wang \& Smith, 2013). And in the mobile-based learning community, the learning outcome is guaranteed by the degree of student involvement. But we cannot expect that students automatically take part in the teaching and learning activities, so there must be some levels of teacher supervision and some rewards or incentives to seduce them into it, such as the credits. Other than this, the learning materials need to be related to the assessment to "push" student to learn.

The environment of the learning community is also an influencing factor to learner's participation. People are very reluctant to express themselves in a group when the members are strangers. They have a fear that there will be retribution when they say something wrong, or in other words, the communication environment is neither open nor safe. A mutual trust needs to be found among the group members. So there may be some additional criteria to follow: (1) designing assessments according to the learning material; (2) mutual trust among group members; and (3) prompt feedbacks from teachers are needed.

\section{WeChat-Based Flipped Classroom and Its Application}

Based on the above theories, the design of teaching model based on WeChat platform, constructs the 
real-time interaction between teachers and students, and therefore, enhances the teaching effect. The model is based on the widely used WeChat app on mobile phone. It reconstructs the business English knowledge structure according to the teaching target, and then constructs a multiple-dimensional interactive teaching model.

\section{Building WeChat Platform and WeChat Group}

A communication platform between teachers and students is built based on WeChat in this experiment. Teachers firstly apply for WeChat public platform account to carry out flipped class teaching, and build interactive and personalized independent learning network environment of "public platform-WeChat group -instant communication". Students can conduct personalized learning with learning materials from the public platform. They can have discussions with teachers and schoolmates in WeChat group when encountering a problem. They can also ask for personalized instruction directly from teachers. After building the communication platform between teachers and students, the next step is to conduct targeted and relevant teaching process.

\section{Posting Learning Materials and Relevant Tasks Through the Public Platform and WeChat Group}

One week prior to the course, teachers are supposed to release videos or other learning materials of next course for independent study through the public platform and WeChat group, at the same time assign tasks and questions related to the materials. Students are required to refer to materials in advance and get ready for class discussion or giving speech in the classroom.

\section{Independent Learning on the WeChat Platform, and Online Communication With Teachers}

The students have access to relevant teaching videos, listening materials on the public platform. When encountering learning difficulties, they can discuss with teachers and classmates in WeChat group and solve the problems during the study in time so as to promote the understanding of knowledge (Shen \& Liu, 2013). During the process of independent learning, the students can complete the course at their own pace, and have discussion and communication with teachers and classmates in WeChat group. In this process, the teachers provide students with personalized guidance to support students' online independent learning. It not only greatly improves the students' classroom activity and makes students apply and review the learned knowledge, but the teachers can also find students' issues and give them guidance in the process.

\section{Teaching Activities in Class}

Business English teaching is more and more applied-oriented, which requires students to have profound theoretical knowledge and rich practical experience. Therefore, in the flipped class teaching, teachers should design applied tasks in advance and let the students solve practical problems in the group discussion and practice, which can put the basic knowledge acquired in the pre-class preparation into application in the classroom, thus improving their comprehensive ability of language. While the teachers encourage students to learn collaboratively, they should encourage students to publish their views in WeChat group, which facilitates sharing among learners. In this process, the teachers are supposed to give personalized guidance to WeChat groups and students, solve the problems in real time and help them better complete the tasks, and finally realize the supposed teaching goals. In this way, teachers change their roles to improve students' participation ability and learning initiative, in the process of solving real problems, the students have chance to verify their classroom knowledge, which accelerates internalization of new knowledge. 


\section{The Experiment of WeChat-Based Flipped Class Teaching Mode}

\section{Case Design of Language Teaching Based on WeChat Platform}

The author has conducted pre-school analysis on 50 students by issuing questionnaire, according to the statistics, 50 students have smart phones, and are regular Internet surfer via their mobile phones. Fifty students use WeChat. WeChat's most highly used functions are shown in Figure 1. On learners' acceptance of WeChat aided flipped class teaching, 47 students want to try, while three are neutral, without anybody rejecting it.

The author has found that students' frequency of WeChat usage is inverse proportional to their language proficiency. High achievement students have a lower frequency of WeChat usage, while the frequency of WeChat usage is higher for those students whose academic achievements are slightly backward. The author has also found that, among the usages of WeChat functions (see Figure 1), one of the most highly used functions of WeChat is textual communication. Basically, all students use friend circle to share information, and some closely related students use group chat function.

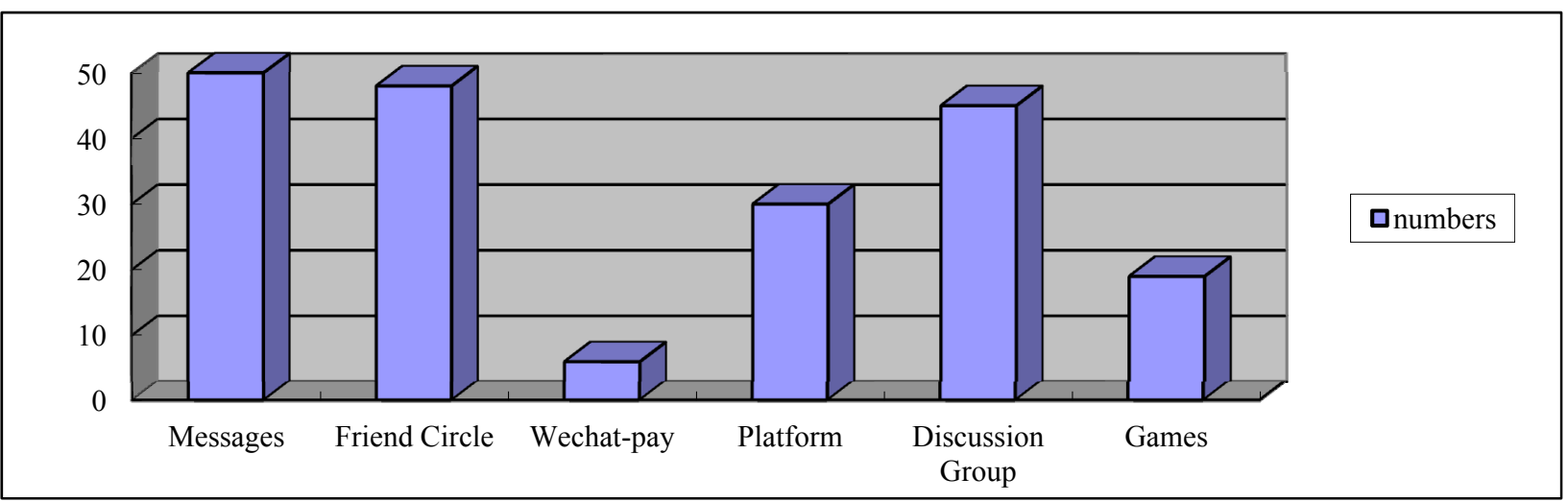

Figure 1. Most highly used functions of WeChat.

The author takes the platform function and group chat function as the main tools of class communication, and establishes different discussion groups according to different subjects so as to help the students to discuss, and therefore, to promote communication between top students and those who fell behind. This is a great way to lead students to share all kinds of learning materials and learning experience, and to promote the teaching reform smoothly. Taking the text book Market Leader book 3 unit 5-"Stock Market" as an example, the author has established a specific teaching plan based on WeChat platform.

\section{Effect Analysis}

With a one-semester reform of flipped classroom, WeChat platform has substantially improved communication between teachers and students as well as communication among students. In the end of the semester, the author has accumulated quite a lot of texts, pictures, and audio and video data, which are rich and first-hand data for the comprehensive promotion of digitization. After the final exam, classes which have participated in the teaching reform testing speak highly of this teaching mode, and their learning satisfaction has reached $86 \%$, their satisfaction for independent learning has reached $89 \%$, for interactive communication has been up to $89 \%$, for knowledge extension is $80 \%$, for easiness of operation is $74 \%$, for learning contents is $89 \%$, and for learning atmosphere is $83 \%$. Most students think WeChat platform college English teaching model based on WeChat has helped their English learning a lot, and they think that this approach is helpful to create a comprehensive language learning atmosphere. The students also think WeChat has increased a lot of 
opportunities for practicing language. When they encounter problems in the process of learning, they are able to communicate more with teachers and classmates, and it is a great help for preparing for final test, such as CET (College English Test). Besides, WeChat is also helpful to improve communication and share among students as well as improve their oral English. In order to further explore whether there is existing difference in teaching effect between WeChat aided flipped class and conventional one, the author has selected and made comparison between samples of mid-term exam results without WeChat aided teaching and the results of final exam with WeChat aided teaching. According to the calculation of SPSS (Statistic Package for Social Science) software, the results in Table 2 are separated into two parts: Levene's homogeneity test of vriance, which is used to judge the homogeneity of the population variance. Here, $F=2.908, p=0.095$, significance level $\alpha=0.05$, and probability $p>0.05$, meaning that the variance is homogeneous and variances of two groups are not significantly different; homogeneity test of the selective variance with $t=6.172, p=0$, and $p<0.05$, reaches the significance level of 0 . Therefore, average performance of both groups is varied significantly, in other words, the test performance of the experimental group is obviously higher than the other. And the mean grade in the final exam is 79.74 , which is greater than the mid-term grades' mean value 76.86 , and it shows that flipped class has significantly improved students' performance.

Table 2

Sample T-test

\begin{tabular}{|c|c|c|c|c|c|c|c|c|c|}
\hline \multirow[t]{2}{*}{ Scores } & \multicolumn{2}{|c|}{$\begin{array}{c}\text { Levene's test for } \\
\text { variances } \\
\text { equation } \\
\end{array}$} & \multicolumn{3}{|c|}{ T-test for mean equation } & \multirow[b]{2}{*}{$\begin{array}{l}\text { Mean } \\
\text { difference }\end{array}$} & \multirow[b]{2}{*}{$\begin{array}{l}\text { Std. } \\
\text { deviation }\end{array}$} & \multirow[b]{2}{*}{ Lower } & \multirow[b]{2}{*}{ Upper } \\
\hline & $\mathrm{F}$ & Sig. & $\mathrm{t}$ & df & Sig. (2-tailed) & & & & \\
\hline \multirow{2}{*}{$\begin{array}{l}\text { Equal variance } \\
\text { assumed } \\
\text { Equal variance not } \\
\text { assumed }\end{array}$} & \multirow{2}{*}{2.908} & \multirow{2}{*}{0.095} & 6.172 & 38 & 0.000 & 13.75000 & 2.23453 & 9.23460 & 18.21530 \\
\hline & & & 6.172 & 33.067 & 0.000 & 13.75000 & 2.23453 & 9.21510 & 18.23780 \\
\hline
\end{tabular}

\section{Discussion of Findings}

Mobile learning platform based on WeChat assists the flipped class. This research focuses on the effectiveness of flipped class. The most relevant factor to the effectiveness of learning is the participation of learners on the platform. If the students can actively cooperate with teacher's teaching arrangement, and try as hard as they can to finish learning tasks, then their effectiveness of learning will be improved. Of course, if the learning tasks are related with students' usual grades, then students' participation is forced to be improved to a certain degree. In addition, the following points are also helpful to improve students' consciousness and initiative, so that students are subjectively more willing to participate in WeChat platform language learning. The author has put forward the following suggestions based on the research:

\section{The Length of the Videos in the Flipped Class Should Be Limited}

The statistical results of Khan's course and the neurological research show that generally people's duration of effective attention is about 10 minutes (Liu \& Jiang, 2015). Therefore, it is supposed to do a certain kind of micro process to the independent materials. The core contents of independent study video aim at a certain specified knowledge or teaching videos of certain lecturing related materials. The goal of lecturing should be clear, with a distinct theme and concise content. The duration of video should be limited within 3-10 minutes, the audio materials should be limited within five minutes, and the reading materials also should not be too long, 
so as to facilitate students to make full use of spare time to study via mobile phones. To provide students learning materials within their effective attention range can also guarantee the independent learners' participation in the WeChat platform.

\section{WeChat Learning Platform Emphasizes the Interactive Function and Helps Students Solve Complicated Problems During Independent Learning}

Students' study on new knowledge is done with the support of mobile platform. The learning materials need to be presented via mobile learning platform. Therefore, the mobile learning platform should possess content interaction function to facilitate a timely communication with teachers or classmates for discussing difficult points (Tong \& Zhai, 2015). If students fail to break through some difficult knowledge points in time when conducting independent study, it is likely to affect their following learning, which may lead to undesirable overall effect of independent study; in the period of the class teaching, if the difficult points have not been solved in time, the students surely have an undesirable internalization effect of knowledge. Therefore, when students encounter difficult points, except their subjective initiative, they had better seek for advice and ask for help from others. The teachers should also provide personalized guidance to the students as much as possible and help students break through as soon as possible.

\section{Teachers Should Change the Way to Evaluate and Improve the Learners' Participation}

Flipped class is greatly different from conventional class in structure. The evaluation approach of conventional classroom does not apply to flipped class. Therefore, teachers should change the way which they evaluate students in time. They should focus not only on evaluation of students' learning results, but also on their study process. Teachers should also do their best to include students' independent study and classroom performance into the new evaluation system, to fully motivate the students' enthusiasm, thus to improve learner's participation.

\section{Pay Attention to the Cultivation of Students' Comprehensive English Ability}

If the students want to benefit from flipped class, they should adapt to this teaching mode at first. The successful implementation of flipped class requires students to possess comprehensive abilities, such as: independent learning, information literacy, collaborative study, language expression, and self-control. However, under the long-term impact of conventional education, students' existing abilities are not so satisfactory. Therefore, we should pay much attention to the cultivation of students' comprehensive ability and help them better adapt to teaching mode of flipped class.

\section{Conclusions}

The one-term experiment has proved that flipped class fully reflects the teaching idea of "students are the main body, and teachers are the lead". Since the implementation of flipped class, the students' abilities of independent study, collaborative learning ability, expression ability, and lecturing effect have achieved certain improvement. College English teaching mode based on WeChat platform is a success. It completes the course target, expands the students' horizons, and cultivates the harmonious relationship between teachers and students. In spite of these, compared to the traditional teaching mode, it requires teachers to spend more time. If the teachers do not engage or dominate from the start to the end, this pattern hardly works. Moreover, WeChat is an interactive tool, and it pays much attention to the accumulation of digital information. Mobile teaching platform, the rear-end of WeChat, is the key factor behind the blooming development of college English 
teaching mode. Timeliness, interactivity, and extensiveness of WeChat have great significance on reforming college English teaching mode; meanwhile, they provide a solid theoretical and applied platform for in- and after-class study of college English (Fan \& Ma, 2015). Although WeChat aided flipped class has made some success, it needs continuous practice, exploration, and finalization step by step along with the advance of science if it acts as an example and reference for our country's teaching reform of advanced education.

\section{References}

Colpaert, J. (2004). From courseware to coursewear? Computer Assisted Language Learning, 17(3-4), 261-266.

Comas-Quinn, A., \& Mardomingo, R. (2009). Mobile blogs in language learning: Making the most of informal and situated learning opportunities. ReCALL, 21(1), 96-112.

Fan, W. X., \& Ma, Y. (2015). A practical study in the flipped classroom based on WeChat under environment of mobile learning. Education Research, 21, 90-97.

Johnson, L., Adams Becker, S., Estrada, V., \& Freeman, A. (2014). NMC, horizon report: 2014 higher education edition. Austin, Texas: The New Media Consortium.

Khan, S. (2011). Let's use video to reinvent education. Retrieved from http://www.ted.com/talks/salman_khan_let_s_use_video_ to_reinvent_education

Liu, H. M., \& Jiang, X. Y. (2015). A design and teaching practice of college English teaching based on WeChat platform. Foreign Language and Literature, 31, 138-143.

Liu, T. Y., \& Chu, Y. L. (2010). Using ubiquitous games in an English listening and speaking course: Impact on learning outcomes and motivation. Computers \& Education, 55(2), 630-643.

Miangah, T., \& Nezarat, A. (2012). Mobile-Assisted language learning. International Journal of Distributed and Parallel Systems (IJDPS), 3(1), 309-319.

Qiu, D. Y. (2014). WeChat changed the world. Beijing: China Wealth Press.

Rueckert, D., Kiser, R., \& Cho, M. (2012). Oral language assessment made easy via VoiceThread! Proceedings from TESOL International Convention and English Language Expo. March 28-31, Philadelphia, PA.

Shen, S. S., \& Liu, Q. (2013). An analysis on flipped classroom based on e-booking. China E-education, 12, $107-111$.

Stockwell, G. (2010). Using mobile phones for vocabulary activities: Examining the effect of the platform. Language Learning \& Technology, 14(2), 95-110.

Sung, Y. T., Huang, C. C., \& Chang, K. E. (2006). The design and application of a mobile devices-based real time formative assessment system. Proceedings from the Meeting of the IADIS International Conference Mobile Learning. July, Dublin, Ireland.

Tong, X. J., \& Zhai, X. R. (2015). Research of marketing teaching mode based on WeChat platform. China Educational Technology \& Equipment, 370, 137-139.

Wang, S., \& Smith, S. (2013). Reading and grammar learning through mobile phones. Language Learning \& Technology, 17(3), 117-134.

Zhang, H., Song, W., \& Burston, J. (2011). Reexamining the effectiveness of vocabulary learning via mobile phones. TOJET: The Turkish Online Journal of Educational Technology, 10(3), 203-214. 